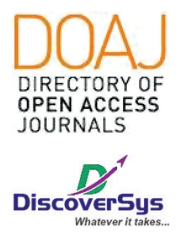

Published by DiscoverSys

\title{
Ketepatan ultrasonografi dan mammografi dalam mendiagnosis wanita dengan kanker payudara di RSUP Sanglah Denpasar
}

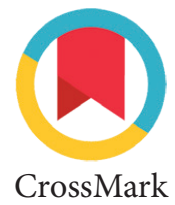

\author{
Cokorda Agung Abi Baruna, ${ }^{*}{ }^{*}$ I. B Tjakra Wibawa Manuaba²
}

\section{ABSTRACT}

Introduction: The high incidence of breast cancer in women, accompanied by delays in making contact with medical personnel and the absence of good early detection contribute to the very high mortality caused by breast cancer. Early detection using ultrasound and mammographic modalities plays an important role in the early diagnosis of breast cancer which will have an impact on the survival of patients. This study aims to compare the diagnostic values of ultrasonography and mammography compared with histopathological features in patients with breast cancer.

Methods: This study used a diagnostic test design with a retrospective approach that compared sensitivity values, specificity, positive predictive value (PPV), negative predictive value (NPV), likelihood ratio from mammography and ultrasonography to histopathological morphology in patients with breast cancer at Sanglah General Hospital Denpasar.

Results: It can be seen that in the total sample, ultrasonography in the toal condition of the sample has a diagnostic value that is very similar to mammography in establishing a diagnosis of breast cancer. Whereas at the age of $>40$ years mammography has a diagnostic test value that is far better than ultrasonography (sensitivity: 85.71; specificity: 83.33; PPV: 92.30; NPV: 76.92; $\operatorname{LLR}(+): 5,14 ; \operatorname{LLR}(-): 0.17)$.

Conclusion: ultrasonography and mammography have almost the same precision in the whole sample, but mammography has a better diagnostic value compared to ultrasonography in people aged $>40$ years.

Keywords: diagnostic test, breast cancer, ultrasonography, mammography.

Cite This Article: Baruna, C.A.A., Manuaba, I.B.T.W. 2019. Ketepatan ultrasonografi dan mammografi dalam mendiagnosis wanita dengan kanker payudara di RSUP Sanglah Denpasar. Intisari Sains Medis 10(3): 684-687. D0I: 10.15562/ism.v10i3.489

\section{ABSTRAK}

Pendahuluan: Insiden kanker payudara yang tinggi pada wanita, disertai dengan keterlambatan dalam melakukan kontak terhadap tenaga medis dan tidak dilakukannya deteksi dini yang baik berkontribusi terhadap angka kematian yang ditimbulkan akibat kanker payudara sangat tinggi. Deteksi dini menggunakan modalitas utrasonografi dan mamografi sangat memegang peranan penting terhadap diagnosis dini dari kanker payudara yang akan memberikan dampak terhadap keberlangsungan hidup dari pasien. Penelitian ini bertujuan untuk membandingkan nilai diagnostik dari ultrasonografi dan mamografi yang dibandingkan dengan gambaran histopatologis pada pasien dengan kanker payudara.

Metode: Penelitian ini menggunakan rancangan uji diagnostik dengan pendekatan retrospektif yang membandingkan nilai sensitivitas, spesifisitas, positive predictive value (PPV), negative predictive value
(NPV), likelihood ratio dari mamografi dan ultrasonografi terhadap gambaran histopatologis pada pasien dengan kanker payudara di RSUP Sanglah Denpasar.

Hasil: Dapat diketahui bahwa pada total sampel yang ada ultrasonografi pada kondisi toal sampel memiliki nilai diagnostik yang sangat mirip dengan mamografi dalam menegakkan diagnosis kanker payudara. Sedangkan pada usia $>40$ tahun mamografi memiliki nilai uji diagnostik yang jauh lebih baik dibandingkan dengan ultrasonografi (sensitivitas: 85,71; spesifisitas: 83,33; PPV: 92,30, NPV: 76,92; LLR (+):5,14; LLR (-): 0,17).

Simpulan: ultrasonografi dan mammografi memiliki ketepatan yang hampir sama unggul pada keseluruhan sampel, namun mamografi memiliki nilai diagnostik yang lebih baik dibandingkan dengan ultrasonografi pada orang dengan usia $>40$ tahun.
${ }^{*}$ Correspondence to:

Cokorda Agung Abi Baruna, Program Studi Pendidikan Dokter, Fakultas

Kedokteran, Universitas Udayana,

Bali-Indonesia

cok_abi@yahoo.co.id
Kata kunci: uji diagnostik, kanker payudara, ultrasonografi, mamografi.

Cite Pasal Ini: Baruna, C.A.A., Manuaba, I.B.T.W. 2019. Ketepatan ultrasonografi dan mammografi dalam mendiagnosis wanita dengan kanker payudara di RSUP Sanglah Denpasar. Intisari Sains Medis 10(3): 684-687. D0I: 10.15562/ism.v10i3.489

\section{PENDAHULUAN}

Angka kematian merupakan indikator umum dari kesehatan sebuah populasi secara keseluruhan, indikator dari status perempuan dalam masyarakat, serta bagaimana fungsi dari sistem pelayanan 
kesehatan yang ada. Tingginya angka kematian wanita itu dianggap sebagai pertanda adanya masalah pada status kesehatan dan pelayanan kesehatan di suatu negara. Oleh karena itu, angka kematian wanita hanya berguna untuk tujuan advokasi, tanpa memberikan informasi tentang apa yang menjadi penyebab kematian wanita atau intervensi apa yang diperlukan untuk mengurangi jumlahnya. ${ }^{1,2}$

Kanker payudara adalah penyebab kematian kedua akibat kanker pada wanita setelah kanker rahim dan merupakan kanker yang paling banyak ditemui pada wanita. Kanker payudara merupakan keganasan pada sel-sel yang terdapat pada jaringan payudara, bisa berasal dari komponen kelenjarnya (epitel saluran maupun lobulusnya) maupun komponen selain kelenjar seperti jaringan lemak, pembuluh darah dan persarafan jaringan payudara. Secara umum angka kejadian kanker payudara lebih rendah pada Negara yang berkembang dibandingkan dengan Negara yang sudah maju. Para peneliti meyakini bahwa keadaan sosioekonomi, perubahan gaya hidup serta perubahan pola menstruasi, ternyata berkaitan dengan peningkatan risiko untuk terjadinya kanker payudara. ${ }^{3,4}$

Kanker payudara ini sendiri merupakan salah satu masalah yang besar yang dialami para penduduk di Indonesia. Contohkan saja di bali, masalah kanker payudara masih sangat banyak terjadi, dan kebanyakan memiliki prognosis yang buruk. Salah satu penyebab buruknya prognosis ini ialah pasien datang ke rumah sakit untuk memeriksakan dirinya tersebut sudah terlambat atau kankernya sudah mencapai stadium yang parah. Hal ini selain dapat disebabkan oleh kehidupan sosial ekonomi, dapat juga disebabkan karena kurangnya edukasi daripada masyarakat tentang

Tabel 1

\begin{tabular}{lc}
\hline Karakteristik & $\mathbf{n = 6 0}$ \\
\hline Usia (n,\%) & \\
$<40$ tahun & $15(25 \%)$ \\
$>40$ tahun & $45(75 \%)$ \\
Asal Daerah (n,\%) & \\
Denpasar & $14(24,6 \%)$ \\
Karangasem & $4(7 \%)$ \\
Klungkung & $1(1,8 \%)$ \\
Bangli & $3(5,3 \%)$ \\
Gianyar & $4(7 \%)$ \\
Tabanan & $4(7 \%)$ \\
Negara & $2(3,5 \%)$ \\
Badung & $7(12,3 \%)$ \\
Luar Bali & $17(24,6 \%)$ \\
\hline
\end{tabular}

pentingnya memeriksakan diri ke rumah sakit untuk mencegah berlanjutnya kanker ke stadium lanjut. Selain itu, khususnya di bali juga, kebanyakan masyarakat percaya akan pengobatan pengobatan tradisional ataupun spiritualistic yang menyebabkan nantinya ketika stadium sudah parah, barulah mereka memeriksakan ke dokter.Padahal teknologi sendiri sudah berkembang sangat pesat, banyak alat alat penunjang dan sistem diagnosis kanker yang selalu berkembang, namun tetap saja angka kematian ini tetaplah terus bertambah. Salah satu modalitas utama untuk deteksi dini ialah dengan alat screening yang dapat mendeteksi apakah ada kelainan dari payudara seorang wanita tersebut. ${ }^{5,6}$ Seiring berkembangnya jaman, terdapat banyak sekali alat penunjang yang dapat membantu mendiagnosis kanker payudara pada seorang wanita. Mammografi, Ultrasonografi, MRI, dan lainnya., ${ }^{3,4}$ Alat alat ini dapat digunakan untuk mendeteksi apakah seorang wanita itu memiliki kelainan atau tidak dari payudaranya yang kemudian dapat pula sebagai penunjang diagnosis untuk kanker payudara itu sendiri. Penelitian ini bertujuan untuk menelusuri nilai diagnostik yang dimiliki pada pemeriksaan mammografi dan juga ultrasonografi yang dibandingkan terhadap gambaran histopatologis pada pasien dengan kanker payudara.

\section{METODE}

Rancangan atau design penelitian ini adalah uji diagnostik. Jenis penelitian ini ialah membandingkan data hasil pemeriksaan terhadap suatu penyakit yang pada penelitian ini merupakan kanker payudara sebagaimana mungkin untuk didapatkan alat mana yang lebih bagus dan akurat dalam mendiagnosisnya. Populasi penelitian ini adalah semua pasien yang terdiagnosis positif kanker payudara di Rumah Sakit Umum Pusat Sanglah, Denpasar, Bali yang dikonfirmasi dengan pemeriksaan histopatologis. Analisis data dalam penelitian ini menggunakan bantuan SPSS versi 16.0. Data yang terkumpul dilakukan tabulasi dan koding untuk kemudian di analisa. Analisa data menggunakan rumus untuk menghitung sensivifitas, spesifitas, nilai ramal positif, dan nilai ramal negatif hasil pemeriksaan imaging dan biopsi patologi anatomi.

\section{HASIL PENELITIAN}

Penelitian ini melibatkan 60 orang dengan kanker payudara yang melakukan pemeriksaan dengan melakukan ultrasonografi dan mamografi dan memilki data rekam medis dari bulan Januari 2012 hingga November 2013 di RSP Sanglah Denpasar. Karakteristik usia da nasal daerah dapat dilihat 
Tabel 2

\begin{tabular}{|c|c|c|c|c|c|c|c|c|c|}
\hline \multirow[b]{2}{*}{ Alat Diagnostik } & & \multicolumn{2}{|c|}{ Histopatologi } & \multirow{2}{*}{$\begin{array}{c}\text { Sensitivitas } \\
(\%)\end{array}$} & \multirow{2}{*}{$\begin{array}{c}\text { Spesifisitas } \\
(\%)\end{array}$} & \multirow[b]{2}{*}{ PPV (\%) } & \multirow[b]{2}{*}{ NPV (\%) } & \multirow[b]{2}{*}{$\operatorname{LLR}(+)$} & \multirow[b]{2}{*}{$\operatorname{LLR}(-)$} \\
\hline & & Positif & Negatif & & & & & & \\
\hline \multirow[t]{2}{*}{ Ultrasonografi (total) } & Positif & 21 & 3 & 72,41 & 75,14 & 87,50 & 33,33 & 1,68 & 0,42 \\
\hline & Negatif & 8 & 4 & & & & & & \\
\hline \multirow[t]{2}{*}{ Mamografi (total) } & Positif & 19 & 5 & 76 & 54,54 & 79,16 & 50 & 1,67 & 0,443 \\
\hline & Negatif & 6 & 6 & & & & & & \\
\hline \multirow[t]{2}{*}{ Ultrasonografi (usia $>40$ tahun) } & Positif & 8 & 5 & 72,72 & 54,54 & 61,53 & 66,67 & 1,59 & 0,50 \\
\hline & Negatif & 3 & 6 & & & & & & \\
\hline \multirow[t]{2}{*}{ Mamografi (usia >40 tahun) } & Positif & 12 & 2 & 85,71 & 83,33 & 92,30 & 76,92 & 5,14 & 0,17 \\
\hline & Negatif & 2 & 10 & & & & & & \\
\hline
\end{tabular}

PPV: positive predictive value; NPV: negative predictive value; LLR: likelihood ratio.

pada tabel 1. Pada tabel 1, ditemukan bahwa pasien dengan kanker payudara cenderung lebih banyak pada usia $>40$ tahun, dan pada penelitian ini kota Denpasar (24,6\%) dan Kabupaten Badung (12,3\%).

Pada tabel 2, diketahui nilai uji diagnostik dari mamografi dan ultrasonografi yang dibandingkan terhadap baku emas diagnostik yaitu pemeriksaan histopatologi. Dapat diketahui bahwa pada total sampel yang ada ultrasonografi pada kondisi toal sampel memiliki nilai diagnostik yang sangat mirip dengan mamografi dalam menegakkan diagnosis kanker payudara. Sedangkan pada usia $>40$ tahun mamografi memiliki nilai uji diagnostik yang jauh lebih baik dibandingkan dengan ultrasonografi (sensitivitas: 85,71; spesifisitas: 83,33; PPV: 92,30, NPV: 76,92; LLR (+): 5,14; LLR (-): 0,17).

\section{PEMBAHASAN}

Rekomendasi oleh Americal College of Radiology dan Society of Breast Imaging saat ini memberikan rekomendasi screening dari kanker payudara menggunakan metode ultrasonografi dibandingkan dengan menggunakan mamografi pada pasien dengan risiko tinggi kanker payudara yang tidak dapat melakukan magnetic resonance imaging (MRI). ${ }^{7,8}$

Ultrasonografi pada melibatkan suatu frekuensi tinggi dari gelombang suara yang melakukan penetrasi terhadap jaringan dari payudara. Terdapat beberapa gambaran karakteristik dari lesi maligna pada ultrasonografi yaitu nonparallel, margin ireguler, shadowing, branch pattern, hypoechogenicity, kalsifikasi, microlobulation dengan akurasi bila apabila ditemukan gambaran tersebut pada ultrasonografi yaitu $88,7 \%, 90,5 \%, 87,1 \%, 85,5 \%, 87,2 \%$, $82,4 \%$. Ultrasonografi merupakan suatu alat yang sangat bergantung terhadap kemampuan operator (operator dependent). ${ }^{3,6}$
Pada sisi lain mamografi memiliki cara kerja yang berbeda dengan ultrasonografi. Proses pemeriksaan payudara manusia menggunakan sinar X dengan meletakkan semacam piringan pada payudara yang dilakukan untuk mencari perubahan anatomis pada jaringan payudara seperti benjolan. Gambar yang diambil dalam proses mamografi disebut mamogram. Dalam mamogram, jaringan payudara yang padat tampak berwarna putih. Bagian payudara lainnya yang terdiri dari jaringan lemak dengan kepadatan rendah akan ditampakkan dengan warna abu-abu. Sedangkan keberadaan tumor akan ditunjukkan dengan gambar berwarna putih sama seperti jaringan payudara yang padat. Mamografi melakukab pemeriksaan secara ototmatis dan tidak memiliki suatu ketergantungan terhadap operator (non operator dependent) seperti pada ultrasonografi. ${ }^{8,9}$

Pada penelitian yang dilakukan oleh Haghighi dkk. Yang melakukan perbandingan terhadap mamografi dan ultrasonografi yang dibandingkan dengan hasil histopatologi pada wanita usia diatas 40 tahun menemukan bahwa pemeriksaan mamografi mampu mendiagnosa 34 kasus benjolan payudara maligna, 1 kasus benjolan payudarah benigna, dan 42 kasus dengan keragu-raguan antara benjolan benigna dan maligna. Pada sisi lain Ultrasonografi berhasil melakukan diagnosos benjolan maligna pada 21 kasus, benjolan benigna pada 2 kasus, dan keragu-raguan antara benjolan maligna dan benigna sebanyak 56 kasus. Apabila dilihat dari penelitian tersebut mamografi cenderung lebih unggul dalam menegakkan diagnosis kanker payudara pada pasien diatas 40 tahun. Hasil tersebut merupakan temuan serupa dengan yang ditemukan oleh peneliti. ${ }^{9}$

Mamografi cederung lebih unggul dibandingkan dengan ultrasonografi pada kelompok usia diatas 40 tahun, hal ini dikarenakan adanya penurunan kepadatan payudara yang lebih banyak di gantikan 
oleh jaringan lemak tubuh, sehingga hal ini akan menimbulkan visualisasi terhadap masa tumor yang lebih baik dan meningkatkan nilai diagnostik dari mamografi. Sedangkan pada orang dengan usia muda, jaringan payudara masih tersusun atas jaringan padat (dense breast) sehingga visualisasi tidak dapat dilakukan oleh mamografi dan hanya menghasilkan gambaran berwarna putih. ${ }^{8-11}$

\section{SIMPULAN}

Secara umum ultrasonografi dan mammografi memiliki ketepatan yang hampir sama unggul, namun ultasonografi cenderung memberikan ketepatan yang lebih bagus pada kelompok usia di bawah 40 tahun, sebaliknya mammografi yang menunjukkan ketepatan yang jauh lebih baik pada kelompok usia di atas 40 tahun.

\section{KONFLIK KEPENTINGAN}

Penulis menyatakan tidak terdapat konflik kepentingan terkait publikasi dari artikel ini.

\section{PENDANAAN}

Penelitian ini tidak mendapatkan pendanaan dari pemerintah ataupun sector swasta lainnya.

\section{ETIKA DALAM PENELITIAN}

Penelitian ini telah mendapatkan persetujuan dari Komite Etik Fakultas Kedokteran Universitas Udayana/RSUP Sanglah Denpasar dengan nomer referensi 2050/UN 14.2.2.VII.14/LP/2016.

\section{DAFTAR PUSTAKA}

1. Merry GM, Mendelson EB. Update on screening breast ultrasonography. Radiol Clin N Am. 2014;52:527-537.

2. O'Connel AM, Irshad A. Breast Ultrasonography. Ultrasound Clin. 2013;8:109-116.

3. Beyer T, Moonka R. Normal mammography and ultrasonography in the setting of palpable breast cancer. The American Journal of Surgery. 2003;185:416-419.

4. Niel BL, Freer PE, Weinfurther RJ, Arleo EK, Drukteinis JS. Screening for breast cancer. Radiol Clin N Am. 2017;55:1145-1162.

5. Feig S. Cost-effectiveness of mammography, MRI, and ultrasound for breast cancer screening. RRadiol Clin N Am. 2010;48:879-891.

6. Durand MA, Hooley RJ. Implementation of whole breast screening ultrasonography. Radiol Clin N Am. 2015;23:1-13.

7. Rella R, Belli P, Giuliani M, Bufi E, Carlino G, Rinaldi P, Manfredi R. Automated breast ultrasonography (ABUS) in the screening and diagnostic setting indication and practical use. Academic Radiology. 2016;18:1-14.

8. Alnaimy NM, Khoumais N. Role of ultrasonography in breast cancer imaging. PET Clin. 2009;4:227-240.

9. Haghighi F, Naseh G, Mohammadifard M, Abdollahi N. Comparison of mammography and ultrasonography findings with pathology result in patient with breast cancer in Birjand, Iran. Electronic Physician. 2017;9(10):5494-5498.

10. Boonlikit S. Comparison of mammography in combination with breast ultrasonography versus mammography alone for breast cancer screening in asymptomatic women. Asia Pac J Cancer Prev. 2014;14(12):7731-7736.

11. Wihandani D, Adiputra P, Supadmanaba I. Low prevalence of Caveolin-1 oncogenic polymorphism G14713A and T29107A among breast cancer patient in Sanglah General Hospital. Bali Medical Journal. 2017;6(3): S109-S112. DOI:10.15562/bmj.v6i3.743

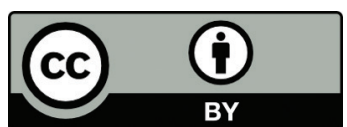

This work is licensed under a Creative Commons Attribution 